\title{
KRONIK DÖNEMDE INME GEÇIRMIŞ HASTALARIN OLFAKTÖR BULBUS HACIMLERININ VE OLFAKTÖR SULKUS DERINLIKLERININ DEĞERLENDIRILMESI
}

\author{
EVALUATION OF THE OLFACTORY BULB VOLUME ANF OLFACTORY \\ SULCUS DEPTH IN PATIENTS WITH CHRONIC STROKE \\ Adil DOĞAN ${ }^{1}$, Veysel BURULDAY ${ }^{2}$, Murat ALPUA $^{2}$ \\ 'Kahramanmaraş Sütçü İmam Üniversitesi Tıp Fakültesi, Radyoloji Anabilim Dalı \\ ${ }^{2}$ Kırıkkale Üniversitesi Tıp Fakültesi, Radyoloji Anabilim Dalı \\ ${ }^{3}$ Kırıkkale Üniversitesi Tıp Fakültesi, Nöroloji Anabilim Dalı
}

öz

\begin{abstract}
AMAÇ: Bu çalışmada, kronik dönemdeki inme geçirmiş hastaların olfaktör bulbus (OB) hacimleri ve olfaktör sulcus (OS) derinliğini değerlendirmek amaçlandı.
\end{abstract}

GEREÇ VE YÖNTEM: Bu çalışma retrospektif ve olgu kontrol çalışması olarak planlandı. Kronik dönemde (>6 ay) inme geçirmiş hastaların OB hacimleri ve OS derinliği ölçümü, manyetik rezonans görüntüleme 1.5-tesla MRG sistemi (Philips MRI Systems, Achieva Release 3.2 Level 2013-10-21, Philips Medical) ile standart kafa coili kullanılarak yapıldı. OB hacim ve OS derinliği ölçümleri, yağ baskılı T2 koronal kesitler kullanılarak yapıldı. İnmeli hastaların verileri sağlıklı kontrol grubu ile karşılaştırıldı.

BULGULAR: Çalışmaya, yaş ortalaması 47.7 \pm 10.7 yıl olan 45 (21 erkek, 24 kadın) inme geçirmiş hasta ile yaş ortalaması $44.5 \pm 8.7$ yıl olan 45 (19 erkek-26 kadın) sağlıklı kontrol dahil edildi. İnme grubu ile kontrol grubu karşılaştırıldığında sağ $\left(34.8 \pm 10.1\right.$ vs. $\left.44.0 \pm 7.4 \mathrm{~mm}^{3}\right)$ ve sol OB $\left(34.9 \pm 10.0\right.$ vs. $\left.49.1 \pm 6.2 \mathrm{~mm}^{3}\right)$ hacimlerinin ortalama değerlerinin inme geçirmiş grupta kontrollere göre belirgin olarak azaldığı görüldü. Olfaktör sulkus derinliği ise sağda gruplar arasında değişiklik göstermezken (7.0 0.0 vs. $7.0 \pm 0.7 \mathrm{~mm}$ ) ve solda inmeli grupta daha yüksek bulundu (7.1 \pm 0.9 vs. $6.7 \pm 0.6 \mathrm{~mm}$ ).

SONUÇ: İnme sonrası kronik dönemdeki hastalarda olfaktör bulbus hacimlerinin azaldığı görüldü.

ANAHTAR KELIMELER: Serebrovasküler olay, Olfaktor bulbus, Olfaktor sulkus, Manyetik rezonans görüntüleme

\section{ABSTRACT}

OBJECTIVE: The aim of this study was to evaluate the olfactory bulb (OB) volume and olfactory sulcus (OS) depth in patients with chronic stroke.

MATERIAL AND METHODS: This study was designed as a case-control and retrospective study. OB volumes and OB depth of the patients with chronic stroke ( $>6$ months) were measured using a 1.5 tesla MRI machine (Philips MRI Systems, Achieva Release 3.2 Level 2013-10-21, Philips Medical) with a standard head coil. OB volumes and OS depth were measured by using fat suppressed T2 coronal images. The data of the stroke patients were compared to the healthy control subjects.

RESULTS: The study included 45 (21 male/24 female) post-stroke patients with the mean age of $47.7 \pm 10.7$ years and 45 ( 19 male/26 female) healthy control subjects with the mean age of $44.5 \pm 8.7$ years. Right ( $34.8 \pm 10.1$ vs. $\left.44.0 \pm 7.4 \mathrm{~mm}^{3}\right)$ and left $\left(34.9 \pm 10.0\right.$ vs. $\left.49.1 \pm 6.2 \mathrm{~mm}^{3}\right) \mathrm{OB}$ volumes were significantly lower in the stroke group than in the control group. Olfactory sulcus depth was similar between the groups on the right side $(7.0 \pm 0.0$ vs. $7.0 \pm 0.7$ $\mathrm{mm})$, however it was higher in the stroke group on the left side (7.1 \pm 0.9 vs. $6.7 \pm 0.6 \mathrm{~mm})$.

CONCLUSIONS: Patients with chronic stroke seem to have decreased $\mathrm{OB}$ volumes compared to the healthy control.

KEYWORDS: Cerebrovascular accident; olfactory bulb;olfactory sulcus, magnetic resonance imaging 


\section{Gíris}

İnme motor fonksiyonlarla beraber birçok sistemin etkilendiği, sakatlık ve ölüm oranlarının yüksek olduğu dünya çapında yaygın bir sağlık problemidir. İnme sonrası hastalarda motor fonksiyonlardaki bozukluklarla beraber kognitif ve duyusal fonksiyon bozuklukları ortaya çıkabilmektedir (1). Diğer yandan, koku duyusu insanoğlunun çevresi ile etkileşiminde rol alan önemli duyusal fonksiyonlarından biridir. Santral sinir sisteminin özelleşmiş lokalizasyonlarında yer alan koku duyusu ile ilişkili alanlar, kokunun farkına varılması ve ayırt edilmesi gibi gelişmiş fizyolojik süreçlerle ilişkilidir. Olfaktör bulbus (OB), olfaktör iletim yolağının ilk durağı olarak, olfaktör sinir liflerinin uzandığı bir çift oval yapıdaki anatomik santral sinir sistemi alanıdır (2). Çalışmalar, OB'yi oluşturan nöral yapılarda sinaptogenezis ve nöroplastik değişikliklerin hayat boyunca devam ettiğini göstermiştir (3). Öte yandan, koku fizyolojisinde ortaya çıkan bozuklukların $\mathrm{OB}$ hacimlerinde küçülmelere neden olduğu manyetik rezonans görüntüleme (MRG) çalışmaları ile gösterilmiştir $(4,5)$. Bununla beraber, literatürde inme geçirmiş hastalarda koku disfonksiyonunun ortaya çıkabileceği gösterilmiştir (6). Ancak inme hastalarında OB hacimleri inceleyen çalışmalar yapılmamıştır. Bu nedenle çalışmamızda, inme gibi santral sinir sistemi üzerinde oldukça yıkıcı olabilecek bir patolojik sürecin, kronik dönemde OB boyutları üzerine olan etkilerini incelemek amaçlandı ve elde edilecek verilerle uygun ve çözümleyici önerilerin yapılması hedeflendi.

\section{GEREÇ VE YÖNTEM}

Çalışmamız retrospektif ve olgu kontrol çalışması olarak planlandı. Çalışmaya iskemik/hemorajik inme geçirmiş kronik dönemde ( $>6$ ay) 45 hasta ile sistemik hastalığı olmayan 45 sağlıklı birey dahil edildi. Parkinson hastalığı, multipl skleroz, temporal lob epilepsisi, Alzhemier demans, paranazal cerrahi girişim öyküsü, paranazal enfeksiyon öyküsü olanlar ve kontrol grubunda kraniyal MRG' de herhangi bir patolojisi olanlar çalışmaya dahil edilmedi.

\section{ETIK KURUL ONAYI}

Mevcut çalışma protokolü için Kahramanmaraş Sütçü İmam Üniversitesi Hastanesi etik kuru- lundan onay alınmıştır. Etik kurul (12.06.2018 tarih ve 14/03 karar no). Retrospektif dizaynda yürütüldüğünden, çalışmamız imzalı aydınlatılmış onam alınmayı gerektirmemektedir.

Olfaktör Bulbus Hacmi ve Olfaktör Sulkus Derinlik Ölçümü: Manyetik rezonans görüntüleme (MRG) incelemeleri, standart bir kafa koili kullanılarak 1.5-tesla MRG sistemi (Philips MRI Systems, AchievaRelease 3.2 Level 2013-10-21, PhilipsMedical) ile yapıldı. OB hacim hesaplamaları için yağ baskılı T2 koronal kesitler kullanıldı. OB sınırları, elektronik işaretleyici kullanılarak manuel olarak işaretlendi ve işaretlenmiş bölgelerin alanları $\mathrm{mm}^{2}$ cinsinden her kesit için hesaplandı. OB hacim değerleri, OB yüzey alanının, kesit kalınlığı ile çarpılması ile $\mathrm{mm}^{3}$ cinsinden hesaplandı (Şekil1).

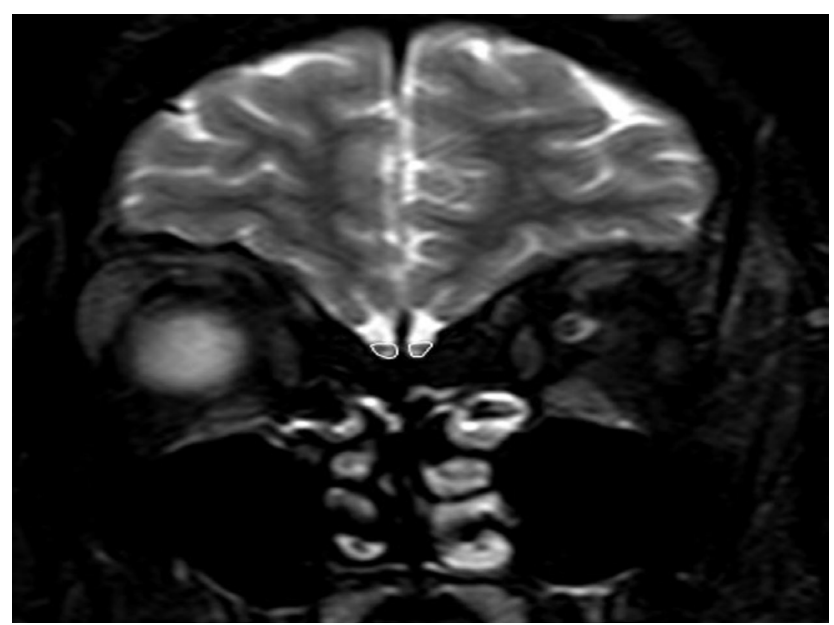

Şekil 1: T2 ağırlıklı coronal MRG SPIR sekansda olfaktör bulbus volum ölçümü; OB yüzey alan ,kesit kalınlığı ile çarpılması ile $\mathrm{mm}^{3}$ cinsinden hesaplanmıştır.

Olfaktör sulkus derinliği; gyrus rektusdan, medial orbital gyrus'a çizilen sanal teğet çizgi ve sulkus içerisinden teğet çizgiye 90 derecelik açı ile bağlanan mesafenin ölçümü olarak $\mathrm{mm}$ cinsinden hesaplandı (Şekil 2).

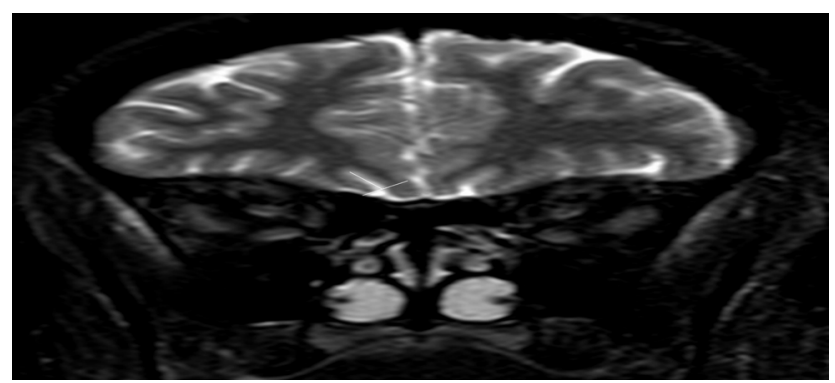

Şekil 2: T2 ağırlıklı coronal MRG SPIR sekansda olfaktör sulkus derinlik ölçümü; gyrus rektus'dan, medial orbital gyrus'a çizilen sanal teğet çizgi ve sulkus içerisinden teğet çizgiye 90 derecelik açı ile bağlanan mesafenin ölçümü olarak mm cinsinden hesaplanmıştır. 
Olfaktör sulkus derinliği ve OB hacim ölçümleri literatürdeki ölçüm yöntemlerine dayanılarak hesaplandı (6). Tüm ölçümler iki radyolog tarafından görüş birliği ile tek ölçüm olarak yapılmıştır.

\section{ISTATISTIKSEL ANALIZ}

Verilerin değerlendirilmesinde SPSS paket programı kullanıldı ve $p<0.05$ istatistiksel olarak anlamlı kabul edildi. Tanımlayıcı istatistikler ortalama, standart sapma olarak verildi. Gruplar arası numerik verilerin karşılaştırılması için normal dağılım kontrol edildikten sonra Student's t testi kullanıldı. Üçlü grup karşılaştırması için ise Tek Yönlü Anova Analizi kullanıldı. Farkın hangi gruptan kaynaklandığını bulmak için ise Post Hoc analizi yapıldı.

\section{BULGULAR}

Çalışmaya yaş ortalaması $47.7 \pm 10.7$ yıl olan 45 (21 erkek,24 kadın ) inme geçirmiş hasta ile, yaş ortalaması $44.5 \pm 8.7$ yıl olan 45 (19 E-26 K) sağlıklı kontrol dahil edildi. Her iki grup arasında demografik veriler açısından istatistiksel bir fark gözlenmedi Tablo 1. Hasta grubu ile kontrol grubu karşılaştırıldığında sağ ve sol OB hacimlerinin ortalama değerlerinin, inme geçirmiş grupta kontrollere göre belirgin olarak azaldığı görüldü. Olfaktör sulkus derinliği ise sağda gruplar arasında değişiklik göstermezken (7.0 \pm 0.0 vs. $7.0 \pm 0.7 \mathrm{~mm}$ ) ve solda inmeli grupta daha yüksek bulundu (7.1 \pm 0.9 vs. $6.7 \pm 0.6 \mathrm{~mm}$ ) (Tablo 1).

Tablo 1: Demografik veriler ve olfaktör bulbus hacimleri olfaktör sulkus derinliğinin gruplar arasında karşılaştırılması

\begin{tabular}{|lccc|}
\hline Değişken & $\begin{array}{c}\text { inme Grubu } \\
(\mathbf{N}=\mathbf{4 5}) \\
47,7 \pm 10,7\end{array}$ & $\begin{array}{c}\text { Kontrol Grubu } \\
(\mathbf{N}=\mathbf{4 5}) \\
44,5 \pm 8,7\end{array}$ & p değeri \\
Yaş (yıl) & $21 / 24$ & $19 / 26$ & $\mathrm{p}>0,05$ \\
Cinsiyet K/E & $34,8 \pm 10,1$ & $44,0 \pm 7,4$ & $\mathrm{p}<0,001$ \\
Sağ OB $\left(\mathrm{mm}^{3}\right)$ & $34,9 \pm 10,0$ & $49,1 \pm 6,2$ & $\mathrm{p}<0,001$ \\
Sol OB $\left(\mathrm{mm}^{3}\right)$ & $7,0 \pm 0,0$ & $7,0 \pm 0,7$ & 0,824 \\
Sağ OS derinlik $(\mathrm{mm})$ & $7,1 \pm 0,9$ & $6,7 \pm 0,6$ & $\mathbf{0 , 0 3 0}$ \\
Sol OS derinlik $(\mathrm{mm})$ & &
\end{tabular}

İnme geçiren hastalar, etkilenen hemisfere göre sağ ve sol olarak ikiye ayrılıp kendi aralarında karşılaştırıldıklarında; sağ hemisfer tutulan grupta erkeklerin daha fazla sayıda olduğu, sol hemisfer tutulumu olan grupta ise kadınların sayısının daha fazla olduğu gözlendi. Etkilenen hemisfere göre karşılaştırma yapıldığında, OB hacimleri ve olfaktör sulkus derinliği ölçümle- ri arasında anlamlı fark gözlenmezken, her iki grupta da OB hacimleri sağlıklı kontrollere göre anlamlı şekilde azalmış olarak bulundu (Tablo 2).

Tablo 2: Tutulan hemisfere göre demografik veriler ve olfaktör bulbus hacimleri - olfaktör sulkus derinliğinin gruplar arasında karşılaştırılması

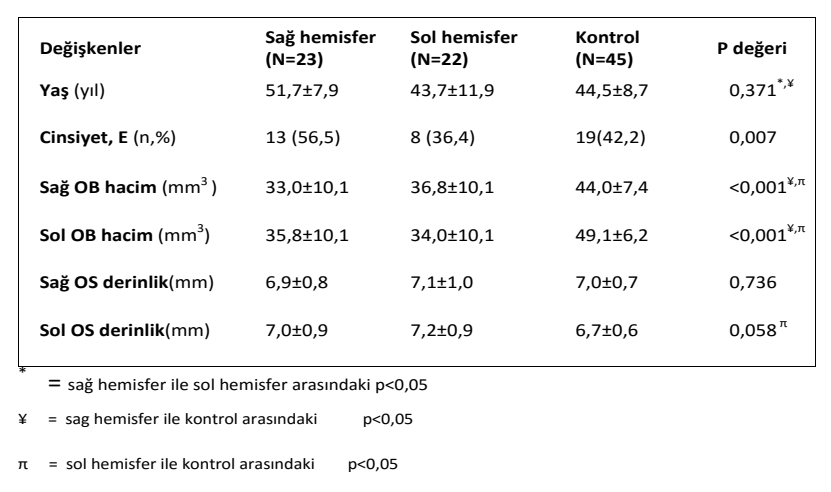

\section{TARTIŞMA}

Santral sinir sisteminin en sık görülen patolojilerinden biri olan inme sonrası ortaya çıkabilen koku disfonksiyonu, literatürde gösterilmiş olmasına rağmen bu hasta grubunda görüntüleme yöntemleri kullanılarak OB hacimleri ile ilgili bir çalışma yapılmamıştır. Kronik dönemdeki inmeli hastalarda, OB hacimlerini incelediğimiz çalışmamızda, temel olarak iki önemli sonuç elde edildi. Bunlardan birincisi; OB hacimlerinin inme geçirmiş kişilerde sağlıklı kontrollere göre anlamlı şekilde azaldığı ve olfaktör sulkus derinliğinin ise arttığıdır. Çalışmanın ikinci önemli sonucu ise, azalmış OB hacimlerinin etkilenen hemisfer ile ilişkili olmadığıdır.

Olfaktör bulbus beyin ön kısmı ve tabanında yerleşik olup amigdala, hipotalamus ve bazal telencefalon gibi inme sonrası sık olarak etkilenebilen önemli anatomik yapıların komşuluğunda yer alır. Bu durum, inme sonrası yeterli kanlanmanın sağlanamaması halinde etkilenen hemisferdeki OB' ye ait nöral yapılarının yıkımına ve bunun sonucu olarak kronik dönemde ortaya çıkacak olan OB hacimlerinde azalmaya neden olabilir. Öte yandan, inmeli hastalarda ortaya çıktığı gösterilen koku duyusu disfonksiyonu, karşı hemisferdeki OB hacimlerinin azalması ile sonuçlanabilir. Bu anormal mekanizma, çalışmamızda gösterilen inmeli hastaların kronik süreçteki $O B$ hacimlerinin kontrollere göre azalmasının patofizyolojik nedenlerinden biri olarak değerlendirilebilir. İnme sonrası kronik 
dönemde olfaktör sulkus derinliği ise artış göstermiştir. Olfaktör bulbektomi yapılmış hayvanlarla yapılan deneysel çalışmalarda, OB' nin inflamatuar süreçlerin organizasyonunda önemli rolü olduğu gösterilmiş ve bulbektomi sonrası inflamasyon ile ilişkili sitokin düzeylerinde dengenin bozulduğu gösterilmiştir (7). Bu durum, inme sonrası santral sinir sisteminde ortaya çkan artmış inflamatuar cavabın, OB fonksiyonlarına ve dolayısıyla OB nöral yapılarına etki ederek, OB hacimlerinde azalmaya neden olabileceği şeklinde değerlendirilebilir.

Alzheimer hastalığı ve Parkinson hastalığı gibi santral sinir sisteminde nörodejenerasyon ile seyreden hastalıkların azalmış OB hacimleri ile olan ilişkisi açık olarak gösterilmiştir $(8,9)$. Bu durum, inme sonrası görülen nörodejenerasyonun da benzer şekilde kronik süreçte OB hacimlerinde azalmayla sonuçlanacağını gösterebilir. Bununla birlikte, çalışmamızın sonuçlarında, etkilenmiş hemisferdeki OB hacimlerinin etkilenmeyen hemisferdeki OB hacimlerinden daha küçük olduğu görüldü. Bu durumun, etkilenen hemisferde ortaya çıkan infarkt ve kanlanma bozukluğu süreçlerinin etkili olduğu bir nörodejeneratif mekanizmanın yansıması olduğu düşünülebilir. İnme ile depresyon ve anksiyete gibi psikolojik problemler arasında sıkı bir ilişki vardır ve inme sonrası yüksek oranlarda depresyon saptanır (10). Depresyonla beraber OB hacimlerindeki azalma geçmiş çalışmalarla gösterilmiştir $(11,12)$. Böylelikle, inme ile depresyonun yakın ilişkisi, $O B$ hacimlerinde azalma ile ilişkili olabilir.

Çalışmamız, retrospektif bir çalışma olduğundan dolayı herhangi bir kurum ve kuruluştan destek alınmamıştır.

Limitasyonlar: Çalışmamızda, bazı kısıtlayıcı durumlar mevcuttur; ilk olarak çalışmamız retrospektif olarak dizayn edildiği için koku fonksiyonunun değerlendiren koku testleri (Sniffin sticks, UPSIT) yapılamadı. İkinci olarak, vaka sayısı her ne kadar az olsa da benzer çalışmalarla kıyaslandığında yeterli olarak değerlendirilebilir. Üçüncü olarak, inme sonrası geçen süre, hastalığın şiddeti ve kullanılan ilaçlar gibi bazı klinik durumlar değerlendirilemedi. Son olarak, tromboembolik ya da hemorajik inmeler ayırt edilmedi.

\section{SONUÇ}

Sonuç olarak, çalışmamızda elde edilen verilerin ışığında; inme sonrası kronik dönemde OB hacimlerinde azalma olabileceği ve bu durumun hastaların uygun ve bütünleyici tedavi yaklaşımları ve günlük yaşam kalitelerinin arttırılması açısından önemli olabileceği sonucu ortaya çıkmıştır. Klinik pratiklerde, inme geçirmiş hastalarda ortaya çıkabilecek koku duyusu bozukluklarının değerlendirilmesi ve multidisipliner yaklaşımlar, hastaların yaşam kalitelerini artırabilecektir. İnme sonrası spesifik koku testlerinin de yapıldığı klinik korelasyonlar ile OB hacmi arasındaki ilişkinin değerlendirildiği prospektif dizaynda ileri çalışmalara ihtiyaç vardır.

\section{KAYNAKLAR}

1. Lai SM, Alter M, Friday G, Sobel E. Prognosis for survival after an initial stroke. Stroke 1995;26:2011-2015.

2. Martines-Marcos A. On the organization of olfactory and vomeronasal cortices. Progress in neurobiology 2009;87:21-30.

3. Graziadei PP, Graziadei GM. Neurogenesis and neuron regeneration in the olfactory system of mammals. III. Deafferentation and reinnervation of the olfactory bulb following section of thefila olfactoria in rat. Journal of neurocytology 1980;9(2), 145-162.

4. Rombaux P, Duprez T, Hummel T. Olfactory bulb volüme inthe clinical assessment of olfactory dysfunction. Rhinology 2009;47:3-9.

5. Buschhüter D, Smitka $M$, Puschmann $S$, Gerber JC, Witt M, Abolmaali ND,"et al". Correlation between olfactory bulbus volüme and olfactory function. Neurolmage 2008;42: 498-502.

6. Duprez TP, Rombaux P. Imaging the olfactory tract. European Journal of Radiology 2010;74:288-298.

7. Wehling $E$, Naess $H$, Wollschlaeger $D$, Hofstad $H$, Bramerson A, Bende M,"et al".Olfactory dysfunction in chronic stroke patients. BMC Neurology 2015;15:199.

8. Rui K, Zhang Z, Tian J, Lin X, Wang X, Ma J,"et al". Olfactory ecto-mesenchymal stem cells possess immunoregulatory function and suppress autoimmune arthritis. Cell Mol Immunol 2016;13:401-8.

9. Doty RL. Olfaction in Parkinson's disease and related disorders. Neurobiol Dis 2012; 46:527-52.2.

10. Thomann PA, Dos Santos V, Toro P, Schönknecht P, Essig, $\mathrm{M}$, Schröder J. Reduced olfactory bulb and tract olüme in early Alzheimer's disease-A MRI study. Neurobiology of Aging 2009; 30(5), 838-841. 
11. Whyte EM, Mulsant BH. Post stroke depression: epidemiology, pathophysiology, and biological treatment. Biological psychiatry 2002; 52.3: 253-264.

12. Negoias S, Croy I, Gerber J, Puschmann S, Petrowski $\mathrm{K}$, Joraschky $\mathrm{P}$ "et al". Reduced olfactory bulb olüme and olfactory sensitivity in patients with acute major depression. Neuroscience 2010;169(1), 415-421.

13. Yang D, Li Q, Fang L, Cheng K, Zhang R, Zheng P,"et al". Reduced neurogenesis and pre-synaptic dysfunction in the olfactory bulb of a rat model of depression. Neuroscience $2011 ; 192,609-618$. 